\title{
A escrita educacional feminina de Maria \\ Lacerda de Moura (1918-1919)
}

\author{
The feminine educational writing of Maria \\ Lacerda de Moura (1918-1919)
}

La escritura educativa femenina de Maria

Lacerda de Moura (1918-1919)

PAULA CRISTINA DAVID GUIMARÃEs (iD)a

\section{Resumo}

Este trabalho examina a escrita educacional feminina de Maria Lacerda de Moura em seus dois primeiros livros: Em torno da Educação, de 1918, e Renovação, de 1919. Professora de escola normal do interior de Minas Gerais, Maria Lacerda de Moura colocou em debate as questões educacionais sob o ponto de vista feminino, sinalizando a importância da mulher na condução da sua educação e da educação da infância. Os resultados apontam duas escritas diferenciadas de Maria Lacerda de Moura: uma voltada para a efetivação da República Brasileira do início do século XX e outra direcionada à libertação da mulher de todo e qualquer domínio social. Nas duas obras, é possível identificar as diferentes relações de poder que permeavam a atuação da mulher no contexto educacional e social.

Palavras-chave: Escrita feminina. Educação. Maria Lacerda de Moura.

\section{Abstract}

This paper examines the feminine educational writing of Maria Lacerda de Moura in her first two books: Em torno da Educação [Around Education], from 1918, and Renovação [Renewal], from 1919. Maria Lacerda de Moura, teacher of a normal school

\footnotetext{
a Universidade Federal de São João del-Rei, São João del-Rei, MG, Brasil. Doutora em Educação, e-mail: pauladavid@ufsj.edu.br
} 
in the countryside of Minas Gerais, put in debates educational issues from the female point of view, signaling the importance of women in conducting their education and childhood education. The results show two different writings by Maria Lacerda de Moura: one focused on the effectiveness of the Brazilian Republic at the beginning of the 20th century; and the other aimed at liberating women from any and all social domains. In the two works, it is possible to identify the different power relationships that permeated the performance of women in the educational and social context.

Keywords: Female writing. Education. Maria Lacerda de Moura.

\section{Resumen}

Este trabajo examina la escritura educativa femenina de María Lacerda de Moura en sus dos primeros libros: Em torno da Educação [Alrededor de la educación], de 1918, y Renovação [Renovación], de 1919. María Lacerda de Moura, maestra de una escuela normal en el interior de Minas Gerais, puso en debate temas educativos desde el punto de vista femenino, señalando la importancia de las mujeres en la conducción de su educación y de la educación infantil. Los resultados apuntan a dos escritos diferentes de Maria Lacerda de Moura: uno centrado en la efectividad de la República brasileña a principios del siglo XX; y otro destinado a liberar a las mujeres de todos y cada uno de los dominios sociales. En los dos trabajos es posible identificar las diferentes relaciones de poder que permearon el desempeño de las mujeres en el contexto educativo y social.

Palabras clave: Escritura femenina. Educación. Maria Lacerda de Moura.

\section{Introdução}

Porque, sobre mulheres, muito pouco se sabe. Virginia Woolf

A epígrafe de Virginia Woolf, retirada de uma palestra dada a mulheres operárias em 1929, provoca-nos ainda hoje. Na época, Woolf chamava atenção para a falta de informações sobre a trajetória profissional das mulheres diante de um contexto patriarcal, em que a sua atuação era reduzida ao espaço privado do lar, como boa esposa e mãe virtuosa.

Mesmo depois de mais de 90 anos, a fala de Woolf ainda se faz operante, sobretudo na historiografia existente, que destina pouco ou quase nada de suas páginas para as mulheres. Para Michelle Perrot (2005), isso se deve a um processo de invisibilidade e/ou apagamento das ações femininas ao longo da história. Vista como inferior ao homem, física e intelectualmente, a mulher foi desconsiderada na 
construção das sociedades, em que somente as ações masculinas tinham reconhecimento e valorização. Assim, o que se vivencia no campo do feminino é uma luta histórica, marcada por batalhas múltiplas e desiguais, quase sempre desconsideradas ou apagadas dos registros oficiais.

Uma das formas de resistência das mulheres para a sobrevivência de seu pensamento se deu por meio da escrita, recurso que possibilitou o registro de suas manifestações e ideias. Segundo Jinzenji (2010), foi a partir do século XIX, com o maior acesso das mulheres ao mundo letrado, que a escrita feminina se tornou a principal forma de captação e circulação do seu pensamento, abrindo espaço, inclusive, para a sua inserção no mundo intelectual. Contudo, é preciso considerar que esse acesso foi consideravelmente limitado às mulheres das classes sociais mais abastadas. Assim, é preciso considerar que as estratégias de dominação do gênero feminino também são mediadas pelas classes sociais, o que implica reconhecer que a categoria gênero não é suficiente para definir todas as relações de opressão impostas ao sexo feminino nas primeiras décadas do período republicano brasileiro.

Neste trabalho, a escrita feminina é entendida como uma produção própria das mulheres. Contudo, isso não significa considerar somente uma categorização sexual simplesmente biológica, mas sim a escrita realizada sob o ponto de vista da mulher e, sobretudo, em função da sua representação, que é particular e específica no eixo da diferença (SCHMIDT, 1995).

A escrita feminina sofreu grandes cerceamentos ao longo da história. Um deles diz respeito ao tempo de que a mulher dispõe para se dedicar a esta arte, já que acumula, por vezes, diferentes jornadas de trabalho. Sobre isso, Virginia Woolf alertava sobre o "fantasma feminino", que insistia em aparecer entre ela e o papel quando tentava escrever algo. Este fantasma era, segundo a escritora, encantador, compassivo e sacrificava-se diariamente, sendo a sua pureza considerada a sua maior beleza. Tal fantasma era o "Anjo do Lar", que dizia que a mulher deveria atuar somente no cuidado da casa e dos seus, sem ter opinião própria, sem dizer o que pensa, sobretudo sobre a moral e o sexo.

[...] segundo o Anjo do Lar, as mulheres não podem tratar de nenhuma dessas questões com liberdade e franqueza [...]. Assim, toda vez que eu percebia a sombra de sua asa ou o brilho de sua auréola em cima da página, eu pegava o tinteiro e 
atirava nela. Demorou para morrer. Sua natureza fictícia Ihe foi de grande ajuda. É muito mais difícil matar um fantasma do que uma realidade. Quando eu achava que já tinha acabado com ela, sempre reaparecia sorrateira (WOOLF, 1996, p. 13).

De diferentes formas, o "Anjo do Lar" circundou e ainda circunda a mulher. Ele é invocado por qualquer pessoa, inclusive pelas próprias mulheres, ao tentar designar espaços, falas e atitudes considerados próprios da alma feminina. Da mesma forma, muitas mulheres se colocaram contra os domínios que são cotidianamente impostos a elas. Algumas usaram a própria escrita na denúncia de toda e qualquer situação que inviabilizasse a vivência plena de uma mulher. Essas batalhas do dia a dia do feminino foram travadas e registradas em diversos documentos que nos são, hoje, fonte de informações sobre essas lutas desconhecidas.

Uma dessas batalhas foi protagonizada pela intelectual e militante da cena pública educacional das primeiras décadas do século XX: Maria Lacerda de Moura. Feminista e anarquista de destaque no período, atuou principalmente por meio da sua escrita, que se fazia contra a desigualdade de direitos entre homens e mulheres, revelando para estas aspectos múltiplos dos enfrentamentos que se apresentavam em um universo preponderantemente masculino.

Na obra de Maria Lacerda de Moura ${ }^{1}$, sobretudo nos livros que publicou, é notória sua defesa em favor dos direitos das mulheres. Neste trabalho, dois desses livros serão analisados: Em torno da Educação, publicado em 1918, e Renovação, de 1919. Neles, é possível identificar uma rica, mas tortuosa história das mulheres para a defesa da igualdade social e de gênero em um contexto em que a submissão do sexo feminino era vista como algo natural e desejável pela sociedade.

\section{Maria Lacerda de Moura: uma mulher multifacetada}

Nascida em Manhuaçu, Minas Gerais, no ano de 1887, Maria Lacerda de Moura teve sua formação e início da trajetória profissional em Barbacena, lugar em viveu desde os seus quatro anos de idade. Apesar de se configurar como uma cidade interiorana e de

\footnotetext{
${ }^{1}$ A obra de Maria Lacerda de Moura é composta por mais de quinze livros, e também por artigos e conferências que foram publicados em jornais.
} 
hábitos tradicionais, cujos costumes se pautavam pela religiosidade e pelo conservadorismo, Barbacena se destacava pelo crescente desenvolvimento urbano, influenciado pela estrada de ferro e pelas influentes lideranças políticas de Minas Gerais. Apesar disso, a família de Maria Lacerda passou por dificuldades financeiras na cidade, o que fez com que o pai a matriculasse em um Externato de Freiras da cidade, o Asilo de Órfãos da Igreja do Sagrado Coração de Jesus e Maria (DIAS, 1999).

Sobre esse período de sua vida, Maria Lacerda relatava que sofreu diversas tensões, se vendo obrigada a conviver com o sectarismo. De um lado, a Igreja Católica e o medo do pecado; do outro, a família e o medo dos espíritos:

$\mathrm{Li}$, conheci de perto o que é o Espiritismo religioso de sessões e preces e o mediunismo, sob todos os aspectos. O medo do inferno foi substituído pelo pavor dos espíritos! Criei-me apavorada, numa atmosfera de horror e crença. Em breve, uma mistura de catolicismo e Espiritismo bailava no meu espírito de criança. Mas, predominava em tudo - o medo (MOURA, 1929, p. 2).

Percebendo o distanciamento da escola católica em relação aos ideais que defendia, o pai de Maria Lacerda logo afasta a filha do externato:

Meu pai, anticlerical, espírita convicto, quando sentiu, talvez, que essa educação teria influência sobre o nosso espírito (meu e de minha irmã, mais moça do que eu) tirou-nos do colégio, onde também, apesar da minha pouca idade (dos 6 aos 10 anos) percebi o espírito de classe, de casta e a injustiça com que os católicos estabelecem a diferença econômica e de dominismo entre os colegiais e respectivas famílias, no trato aos ricos, aos potentados, e, no desprezo e exploração para com os pobres, os humildes e os de cor (MOURA, 1929, p. 2).

Ao completar 12 anos de idade, Maria Lacerda foi matriculada na Escola Normal Municipal de Barbacena, única instituição da região em que poderia prosseguir seus estudos, já que ofertava vagas gratuitas para alunos pobres. Lá, se formou aos 17 anos de idade, quando, também, se casou com Carlos Ferreira de Moura, com quem conviveu durante pouco tempo, se divorciando com a justificativa do sofrimento do marido com o olhar social sobre a evolução intelectual pela qual estava passando:

O "marido" da escritora perde a sua individualidade [...], até o tró-ló-ló classificou-o de "vira-lata". [...], que sorte está reservada ao marido da escritora, ao marido da poetisa ou da pianista? Assim, meu marido, pelo seu nobre caráter, e eu, defendendo a minha dignidade de ser livre, talvez acabemos nos divorciando dessa 
comédia do casamento legal. Para sermos amigos, não precisamos de selo do Estado (MOURA, 1929, p. 2).

Foi na própria Escola Normal de Barbacena que Maria Lacerda de Moura iniciou sua carreira como professora. Responsável pela cadeira de Pedagogia e Higiene, trabalhava com a formação de professores primários, com os conteúdos que envolviam a história da educação, os métodos gerais do ensino, a organização e a legislação escolar, a psicologia infantil e a higiene.

Naquele momento, Maria Lacerda, como muitos de seu tempo, compartilhava da propaganda de difusão da civilização e do progresso, a serem desencadeados, sobretudo, pela instituição escolar reformada, que mobilizava a educação enquanto projeto de nação. Por meio de ideais republicanos, Maria Lacerda pensou e criou possibilidades de transformação da sociedade, utilizando como eixo a educação escolarizada, sobretudo da criança. Prova disso foi a criação, por ela, em 1915, da Liga Barbacenense Contra o Analfabetismo, considerada a primeira a se organizar no Brasil em apoio ao projeto nacional da LBCA (Liga Brasileira de Combate ao Analfabetismo).

Apesar de não ter tido filhos, adotou Jair, um sobrinho, e Carminda, uma órfã carente. Anos mais tarde, romperia toda e qualquer relação com o filho, já que ele teria aderido ao integralismo durante a década de 1930:

Criei uma criança, um sobrinho, eduquei-o ao meu lado, com o meu exemplo, em meio anticlerical, entre revolucionários autênticos - operários, intelectuais livres. Tomei-o aos quatro anos de idade, morou na minha casa, sem interrupção, durante quinze anos. Era meu filho. Chama-se Jair Lacerda Cruz Machado. Por motivos de saúde, saiu de São Paulo, em busca do seu clima natal. [...] Entreguei-o apto a lutar pela vida, com oito preparatórios. Passaram-se anos. A sua atitude de algum tempo me fez desconfiar que Jair entrara para as fileiras integralistas. Ha meia dúzia de dias eu tive a confirmação: não só Jair é integralista como já é tenente. Pois bem: meu filho adotivo morreu. [...] Ele é soldado da Igreja, do Despotismo, do Terror, da Violência pela Violência. [...]. Se amanhã uma "expedição punitiva" vier em minha busca, Jair pode sossegadamente fazer parte do bando, não o reconhecerei no meio dos seus pares (MOURA, 1935, p. 3).

Maria Lacerda relatava que, desde o início da sua trajetória profissional enfrentava oposições às suas ideias: “Que expressões são essas?” "Certas verdades não se diz!’. “Mais cuidado!”. “Não fica bem!'”. "Você vai mal!” (MOURA, 1929). 
É preciso lembrar que a escola e a educação eram, naquele momento, um dos poucos espaços e temas nos quais a mulher escolarizada era autorizada participar. Dentro desse contexto, esperava-se que sua atuação estivesse em sintonia com o que se espera de uma mulher do início do século XX: uma atuação materna e estritamente voltada para a escolarização de seus alunos.

Contudo, a atividade docente em uma Escola Normal já não condizia com o novo papel que Maria Lacerda de Moura começava a assumir: a de feminista e anticlerical. Foi nesse contexto que a professora, junto com algumas de suas alunas criou o jornal A Pétala, em 1918. Com o uso de pseudônimos ${ }^{2}$ publicavam, entre outras, notícias sobre a evolução do feminismo em vários lugares do mundo. Apesar de ter tido poucos números publicados (apenas seis), A Pétala pode ser entendido como a escrita pública inicial de Maria Lacerda sobre os direitos das mulheres e o papel que estas deveriam assumir na sociedade.

É necessário destacar que Maria Lacerda de Moura entendia o feminismo enquanto espaço de vivência e de difusão da liberdade da mulher, podendo ser caracterizado como um feminismo libertário, que se colocava longe de toda e qualquer amarra social, inclusive próprio voto ${ }^{3}$.

Suas ideias foram subsidiadas por autores diversos, que tratavam desde os usos da ciência para a educação — Binet, Claparéde e Maria Montessori — até aqueles que discorriam sobre a concepção de uma escola moderna, entendida sob o viés libertário e anarquista — Francisco Ferrer e José Oiticica.

Mesmo tendo tido uma trajetória de grande visibilidade na esfera da luta pela emancipação feminina em São Paulo a partir do ano de $1921^{4}$, é sobre a escrita de

\footnotetext{
${ }^{2}$ As quatro de suas alunas que participavam da edição do jornal se apresentavam pelos pseudônimos: Resedá, Magnólia, Orchídea, e Miosótis.

${ }^{3}$ Maria Lacerda não acreditava no voto enquanto forma de emancipação da mulher. Para ela, de nada adiantaria o voto já que a mulher não poderia se eleger a nenhum cargo político.

${ }^{4}$ Com a hostilidade que Maria Lacerda passou a enfrentar em Barbacena, a professora decide abandonar a carreira docente e se mudar para São Paulo em 1921, quando engajou-se nos movimentos anarquistas e feministas, participando de intensas greves e atuando, principalmente através de sua escrita. Em 1928 passou a viver em uma comunidade anarquista em Guararem e, em 1937, com a repressão do Estado Novo, retornou por um breve período a Barbacena. Passou seus últimos anos de vida no Rio de Janeiro, onde retomou seus laços com o espiritismo na sua constante busca por um ideal, quer político, quer social, quer, na maturidade, religioso. Morreu em 1945 em uma espécie de exílio individual.
} 
Maria Lacerda de Moura como professora na cidade de Barbacena que este trabalho trata, sobretudo a sua escrita sobre a educação da mulher na sociedade brasileira. É neste contexto que os livros Em torno da Educação, de 1918, e Renovação, de 1919, serão analisados.

\section{Educar-se para educar: o papel da mulher para a efetivação da República Brasileira}

Só sei que, como mulher, devo tentar demonstrar às minhas alunas que, a mulher, no momento atual, melhor que nunca, pode e deve trabalhar pela sua Pátria e pela Humanidade.

Maria Lacerda de Moura, Em torno da educação

Em torno da Educação foi o primeiro livro publicado por Maria Lacerda de Moura. Lançado em 1918 pela Livraria Teixeira, o livro reúne artigos, conferências e discursos produzidos pela professora ao longo das suas atividades na cidade de Barbacena.

Ao que tudo indica, Em torno da educação foi um livro de pouca circulação. De acordo com Dias (1999), naquele período era comum os autores financiarem a produção de seus livros, já que o mercado editorial das primeiras duas décadas do século XX era precário e demandava investimentos daqueles que quisessem publicar seus escritos. Além de serem escassos os pontos de vendas de varejo e praticamente limitados aos bairros mais ricos do Rio de Janeiro e de São Paulo, a maioria dos livros comercializados vinha de Portugal e da França. Nesse cenário, eram raros os autores brasileiros que se aventuravam em escrever sobre áreas que não fossem as de campos seguros para a venda, como os livros didáticos e os livros sobre a legislação brasileira.

Supostamente com poucos exemplares, Maria Lacerda iniciou a distribuição do seu livro entre intelectuais do período e jornais do país e do exterior. Tal atitude pode ser associada ao desejo de visibilidade da sua produção. De acordo com Lévy (1998), essa prática está associada a um tipo específico de intelectual: aquele que ousa sair de sua disciplina, de sua especialidade para imergir em debates necessários 
ao momento. Para o autor, esse ato é fortalecido, ou nasce, por uma autoridade adquirida, seja em um lugar, seja em um espaço. No caso de Maria Lacerda, é possível identificar esse lugar e esse espaço: a posição de professora em uma Escola Normal, instituição notadamente reconhecida e de distinção intelectual no início do século XX.

Segundo Vieira (2015), a existência de muitos intelectuais ligados a projetos educacionais no Brasil no início do século XX não se deu por acaso. A precariedade na oferta e nas condições educacionais fez com que essas pessoas buscassem a ampliação e o aprimoramento da escola, envolvendo também a organização de empreendimentos editoriais, redes de museus, teatros, cinemas e bibliotecas, atividades artísticas, esportivas e de lazer, entre outras políticas e ações culturais. O autor ainda acrescenta que, assim como variava o prestígio entre esses intelectuais, variavam, também, as suas estratégias de lutas e conquista de visibilidade. No caso de Maria Lacerda, a estratégia utilizada para dar visibilidade aos seus trabalhos foi a publicação de livros sobre os desafios da educação, sobretudo da educação da mulher e da criança. Sobre a criança, sinaliza que a educação deveria atuar não só com relação à instrução, mas também na formação mais ampla do futuro cidadão, alterando ou moldando seus hábitos e costumes. Já com relação à educação da mulher, esta deveria agir na sua conformação do papel de mãe, justamente para que a educação da criança pudesse se efetivar.

“Carecemos de mães!” A primeira frase do livro demostra que a professora mineira creditava à mulher uma missão que, segunda ela, lhe foi dada pela natureza: o de ser mãe. Maria Lacerda defendia que as mães deveriam se voltar à educação dos filhos ainda na tenra idade, no espaço do lar, sem a necessidade de enviá-los à escola. Também seria papel da mãe ensinar atitudes saudáveis de cuidados com o corpo e hábitos morais condizentes com a idade. Segundo ela, só assim as crianças teriam plena formação moral, condição primordial para seus deveres de cidadãos para com o Brasil do futuro.

Senhoras! Quereis conhecer o valor de um povo? Ide examinar os lares e observar as mães... preocupemo-nos um pouco mais com o destino do nosso querido Brasil. $\mathrm{Na}$ América do Norte, onde o povo tem fé na educação e respeito pelas instituições pedagógicas, há grandes industriais que, aceitando operários adolescentes, não 
procuram indagar dos adolescentes dos pais, mas exigem documentos sobre o procedimento e o caráter das mães! (MOURA, 1918, p. 14).

Caberia às "queridas patrícias" erguer o caráter nacional, fazer o Brasil crescer em termos de civilidade e progresso através da criação de seus filhos e da educação de seus alunos. Entretanto, isso só seria possível se essas mulheres se educassem primeiro, se adquirissem conhecimentos que pudessem auxiliá-las nessa missão. Só assim poderiam fazer propagandas decisivas contra o jogo e o álcool, grandes males sociais que estariam conduzindo a população à doença, à loucura, à ruína moral e também ao suicídio, males que assolavam o país.

Para Maria Lacerda a verdadeira religião da mulher seria a maternidade: “minhas leitoras, vós o sabeis, melhor que eu — é a maternidade! Toda mulher nasceu para ser mãe” (MOURA, 1918, p. 87). É importante observar que, ao alertar a mulher sobre a importância de sua participação para a melhoria da nação brasileira através do seu papel de mãe, Maria Lacerda adota um discurso já bastante difundido pela sociedade brasileira naquele momento.

Maria Lacerda alegava que a mulher agia como um objeto de adorno e de gozo e só se preocupava consigo mesma, com seus enfeites, com sua beleza. As mães procuravam educar as filhas nas artes decorativas. O homem, por seu lado, procurava demonstrar que sabia apreciar o sexo fraco nos seus gestos, nas suas atitudes plásticas, na sua fraqueza, e tudo isso concorria para o mesmo e único fim: conservar eterna e fresca a juventude da mulher.

A eletricidade presta um grande concurso neste afã interminável e as massagens, os aparelhos trabalham em continuo ideal de aperfeiçoamento, tirando rugas, dando cores, corrigindo senões. Os anúncios de perfumarias, loções e preparados diversos tomaram os primeiros lugares nos grandes jornais, nas principais revistas e nos lugares preferidos pela gente de tratamento. Diz-se mesmo que a felicidade da mulher depende da beleza! (MOURA, 1918, p. 128).

A tríade mãe-esposa-dona de casa compunha o discurso sobre a mulher no início do século XX, sendo expresso em revistas femininas, ditado pela Igreja e prescrito por médicos e juristas. O próprio Código Civil da República, aprovado em 1916, deixava claro que o papel que deveria ser desempenhado pelas mulheres na 
sociedade seria o de esposa e mãe. Sua identidade deveria ser caracterizada como "o lar feliz", pela subordinação ao homem, chefe da sociedade conjugal:

Vários preceitos do Código Civil de 1916 sacramentavam a inferioridade da mulher casada ao marido. Ao homem, chefe da sociedade conjugal, cabia a representação legal da família, a administração dos bens comuns do casal e dos particulares da esposa segundo o regime matrimonial adotado, o direito de fixar e mudar o local de domicílio da família. Ou seja, a nova ordem jurídica incorporava e legalizava o modelo que concebia a mulher como dependente e subordinada ao homem, e este como senhor da ação (MALUF; MOTT, 1998, p. 375).

Maria Lacerda defendia a beleza moral em detrimento da "frivolidade" feminina, dizendo que ela seria a única que traria à mulher a presença amável, a bondade e a pureza. "Essa é a beleza que zomba dos anos, das rugas, dos cremes e das massagens elétricas” (MOURA, 1918, p. 129). Para a professora, já não seria mais permitido às mulheres permanecerem sob tal domínio, que as absorvia, inquietava e impressionava, mas que só se dava pela falta de instrução, da qual a mulher estaria carente havia muito tempo, tendo seus olhos fechados à compreensão de todos os acontecimentos humanos. Contudo, a autora anuncia que seria possível uma emancipação da mulher diante dessas práticas, e que isso já estaria acontecendo.

A emancipação feminina se daria pela elevação das mulheres por elas mesmas. Era preciso que se ocupassem de si e das outras, tornando-se "protetoras das suas irmãs ignorantes e infelizes” (MOURA, 1918, p. 129). O desejo de Maria Lacerda era ver as suas patrícias unidas para a "santa cruzada" de preparo do futuro, entregando sua inteligência à cultura, ao progresso do país.

Alguns estudos, como os de Louro (2009), Rago (2014), Fernandes (2003), Jinzenji (2010), indicam que, ainda no século XIX, já se apontava a importância de uma educação mais ampla para a mulher, vinculando-a ao avanço da sociedade, à melhoria da saúde da família e à formação dos futuros cidadãos. Alguns defendiam que essa educação deveria se dar em paralelo com uma formação cristã — leia-se, católica -, considerada a mais importante fonte de formação moral da época, na qual a mulher deveria buscar para si a imagem da Virgem Maria. Para outros, inspirados nas ideias positivistas e cientificistas, a educação da mulher, justificada pela ligação com a sua função materna, deveria ocorrer no sentido de afastá-las das 
superstições que faziam parte do cotidiano de criação dos filhos e de incorporar as novidades da ciência, sobretudo as advindas da puericultura, da psicologia e da economia doméstica.

Ao que tudo indica, Maria Lacerda seguia a segunda linha desses discursos, considerando a ciência como a chave de leitura para a formação da mulher. Entretanto, para a professora mineira, a ciência, mais do que formar para a maternidade, cumpriria um papel a mais: o de libertar a mulher de uma suposta condição de inferioridade diante do homem.

Para creditar valor ao papel que queria dar à mulher naquele momento, Maria Lacerda teria de ir contra uma sociedade que ainda defendia a superioridade masculina, justificada através de dados científicos, sobretudo os antropométricos.

Para os antropologistas do final do século XIX e início do XX, os lóbulos frontais do homem eram maiores, mais ricos que o da mulher, o seu cérebro seria mais pesado, sendo a inteligência masculina proporcional ao desenvolvimento cerebral. Sobre a inferioridade da mulher: dizem que é mais medula, enquanto que o homem é mais cérebro, dizem os estudiosos, provando-o experimentalmente (MOURA, 1918, p. 123).

Para combater tais ideias, Maria Lacerda também se valia dos dados antropométricos. Argumentava que, apesar de o cérebro da mulher ter evoluído pouco em relação ao do homem, o processo educacional o estava fazendo evoluir e poderia fazer ainda mais. Para essa argumentação, utilizou as informações do livro A mulher e a Sociogenia, de Tito Lívio de Castro, médico brasileiro que se inseriu no debate em defesa da capacidade intelectual da mulher no final do século XX.

A mulher e a sociogenia, discutindo convincentemente a inferioridade da mulher, chega a dizer: "A mulher tem um cérebro e um psicose infantil porque e só porque foi submetida a uma seleção que procurou esse resultado", e mais adiante "o cérebro feminino só espera o fermento da educação para evoluir" (MOURA, 1918, p. 123).

Desacreditada dos difundidos dados antropológicos sobre a mulher, advindos, sobretudo, dos estudos da craniometria do final do século XIX e início do $\mathrm{XX}$, a professora afirmava que havia exageros nos dados quantitativos e muitos erros em suas informações: 
Topinard que, tendo estudado quatrocentos crânios da África, medindo cem crânios de cada raça, nada comprovou. Flowis, Dawis, Mantegazza e outros antropologistas também asseguram que esses quadros variam e que nada se pode provar ainda, nesse terreno (MOURA, 1918, p. 124).

A partir dessa fala, Maria Lacerda apoia sua defesa sobre a mulher, asseverando que tais pesquisas, além de falhas, seriam, também, tendenciosas, pois apontariam sempre a inferioridade da mulher diante daquele que não queria dividir o posto de comando na sociedade:

O homem, não satisfeito ainda de haver determinado a si próprio o primeiro lugar na sociedade, quer demostrar que a mulher lhe é inferior morfologicamente, e que a natureza a colocou entre ele e o macaco. Com maior sinceridade contraponho eu a tais argumentos um punhado de outros, que não são discutíveis e que demonstram que o homem é mais vizinho do macaco do que a mulher. É doloroso observar como, até na anatomia, o orgulho masculino tem perturbado o sereno exame dos fatos (MOURA, 1918, p. 124).

Maria Lacerda queria demonstrar que a pretensa inferioridade intelectual da mulher teria sido consequência da falta de atividade de seu cérebro. Para ela, o cérebro da mulher, uma vez exercitado, seria suscetível de desenvolvimento. Assim, seria necessário aproveitar a força dispersiva da mulher, adaptá-la e apropriá-la ao desenvolvimento físico-social, fazendo desaparecer a histeria, considerada por ela característica da decadência da ação cerebral; a sensibilidade exagerada, que seria prejudicial à força do espírito de justiça; a superficialidade; os preconceitos; a superstição e o espírito de religiosidade. Enfim, era preciso que a mulher raciocinasse de forma mais segura para que o seu cérebro chegasse a conclusões sensatas.

Já na esfera social, a mulher só seria capaz de alcançar o homem se lutasse pelos seus interesses e, consequentemente, pelo interesse da sociedade futura observando e estudando a sua estrutura íntima, conhecendo a sua natureza física, as suas taras psíquicas, bem como a capacidade atual e futura da sua energia mental. Todas deveriam estudar os meios de remover os inconvenientes de sua educação “defeituosa, exibicionista e postiça”, a qual, em vez de preparar mães de família, procurava confeccionar bibelôs vivos (MOURA, 1918, p. 126).

O posicionamento de Maria Lacerda estava em perfeita sintonia com o discurso médico/psiquiátrico do período, que apontava a histeria como uma 
patologia própria do sexo feminino e considerada responsável pelos ataques nervosos das mulheres e pelo seu distanciamento dos deveres na sociedade, sobretudo daqueles relacionados à maternidade.

A histeria foi matéria de grande interesse da medicina brasileira, principalmente a partir das últimas décadas do século XIX, quando as histéricas foram descritas como verdadeiras ameaças à ordem social. Procurando minimizar tal ameaça, nossos médicos se debruçaram sobre as concepções psiquiátricas da histeria, reproduzindo os debates e as controvérsias de além-mar (NUNES, 2010, p. 11).

Como destaca Foucault (1979), ao longo da história de várias sociedades, a histérica foi sendo construída como o modelo perfeito da mulher nervosa e a negação da boa mãe, o que contribuiu para certo descrédito da figura feminina em vários ramos da atividade social, bem como para um direcionamento médico para a sua observação e tratamento.

Da mesma forma, a neurastenia, ou a falta de força de vontade, era vista por Maria Lacerda como uma doença que poderia se manifestar ainda na primeira infância, sendo as próprias progenitoras influências negativas nesse processo. "Quantas crianças há por aí que andam a contar mentiras, a inventar que possuem brinquedos que não existem, a impingir grandezas aos companheiros e a se considerar pequeninos fidalgos?” (MOURA, 1918, p. 135). Ainda aqui, a autora demonstra conhecimento das teses médicas do início do século XX, que levantavam a teoria da degeneração e da hereditariedade, que deu força à tese de que a histeria e a falta de força de vontade poderiam afetar todos aqueles considerados mais frágeis ou que tivessem sido excessivamente expostos às mazelas da civilização, fossem eles homens ou mulheres (NUNES, 2010). Nesse contexto, pode-se afirmar que Maria Lacerda esteve em sintonia com um processo "biopolítico" do cidadão brasileiro no início do século XX, uma espécie de gestão da população, especialmente da mulher, que determinava para esta as melhores formas de se cultivar um corpo saudável e disciplinado (FOUCAULT, 1997).

Ao anunciar que a educação tradicional iria ceder, cada vez mais, lugar a uma ciência experimental, Maria Lacerda sugeria que suas alunas buscassem conhecimentos advindos da psicologia, da fisiologia, da ética e da estética: "há um vasto campo de teorias e de observações que o experimentador precisa 
compreender para tentar aplicar as leis da pedagogia moderna. Estudai muito!" (MOURA, 1918, p. 43). O livro seria a maior necessidade das futuras professoras, a fonte para a capacidade intelectual da mulher dependeria da sua força de vontade para realizar e alcançar seus objetivos. "Indaga, perscruta, volta a página e há de compreender por si mesma" (MOURA, 1918, p. 44).

Na escrita de Maria Lacerda sobre a mulher, há duas posturas diferenciadas. A primeira caminha no sentido oposto de grande parte do pensamento da época, na medida em que defende uma igualdade intelectual entre homens e mulheres, buscando provar que estas também teriam capacidades intelectuais. Nessa posição, usa o discurso científico em favor do sexo feminino para a valorização de suas ações e do seu potencial intelectual. Já a segunda postura se revela mais tradicionalista, posicionando a mulher em lugares já demarcados pela sociedade da época, como a casa e a escola, locais onde desempenharia os papéis já autorizados naquele momento: o de mãe, esposa e professora. Essas funções deveriam ser desempenhadas com o máximo esmero e cuidado pela mulher, numa constante modificação e melhoria de seus hábitos, de sua conduta, enfim, em um constante "cuidado de si" para o seu aprimoramento e, consequentemente, para o aprimoramento da sociedade.

Para Foucault (1984), o "cuidado de si”, ou o "governo de si”, propõe uma atitude reflexiva do sujeito sobre si próprio, sobre suas ações; de modificação de si mesmo em busca de um aperfeiçoamento constante da sua vida, através do governo da própria existência. O pensador ressalta que, por sua vez, o "cuidado de si” estaria diretamente ligado aos "discursos de verdade", àqueles que são aceitos e difundidos pela sociedade, que funcionariam como um código pelo qual se deve construir a si mesmo como sujeito moral, agindo em referência aos elementos prescritivos que constituem tal código. A efetivação desse "cuidado de si" se daria através de determinadas técnicas, chamadas por Foucault (1984) de "técnicas de si", que permitiriam aos indivíduos efetuar, com a ajuda de outras pessoas, um certo número de operações sobre seu corpo e sua alma, sobre seus pensamentos, suas condutas, seu modo de ser, enfim, que ajudariam na transformação desse sujeito a fim de alcançar um certo estado de perfeição. Nesse caso, trata-se de tornar o 
comportamento não somente conforme a uma regra dada, mas, sobretudo, de tentar transformar a si mesmo em sujeito moral de sua conduta (FOUCAULT, 1984).

Como visto, as "técnicas de si" prescritas por Maria Lacerda para a mulher partiam das diferentes demandas que lhes eram atribuídas: mães, esposas, professoras, patrícias. Para desempenhar com perfeição essas tarefas, as mulheres deveriam estudar, conhecer melhor seu próprio corpo e sua capacidade intelectual, aprender mais sobre a criação dos seus filhos e a educação de seus alunos. Esses estudos deveriam estar amparados nas pesquisas científicas da época, consideradas as mais "verdadeiras" para a lida com a grande heterogeneidade humana e social que compunha o país.

Como é possível observar, o posicionamento adotado por Maria Lacerda sobre a mulher, seja sobre a sua capacidade intelectual e seus deveres de mãe, seja sobre o seu papel de professora, esteve ligado a um objetivo maior: a educação da criança, considerada o futuro cidadão, que faria melhorar e progredir a nação brasileira. Era com esse objetivo que alertava a mulher sobre a importância de se educar primeiro, de conhecer as pesquisas científicas que estavam sendo desenvolvidas em países da Europa e nos Estados Unidos.

Em torno da educação traduziu bem esse contexto de utilização da ciência em prol da nação e da República de sua época, envolvendo personagens centrais para essa dinâmica, como a criança e a mulher, que podem ser considerados os pilares da biopolítica de seu tempo. Entretanto, parte desses ideais teve curta duração na trajetória e nos escritos de Maria Lacerda, perdurando o tempo que seguiu antes da próxima publicação, Renovação, que mudaria definitivamente sua posição de defesa da República para a busca de uma sociedade libertária, na qual a mãe, a criança e a ciência assumiriam outros papéis.

\section{A mulher renovada: o novo papel da educação para a mulher}

Moças do meu país: se alguém vos disser que este livro não pode ser folheado por uma menina - não acrediteis. É possível que o classifiquem de mil modos segundo o espírito conservador, tradicional ou 
reacionário. O que é certo é que eu o escrevi para vós e nada há aqui, indigno da donzela mais ingênua ou da mulher mais casta.

Maria Lacerda de Moura, Renovação

Em 1919 Maria Lacerda publicou seu segundo livro: Renovação. Considerado por ela uma produção que rompia com algumas ideias defendidas no livro anterior, a obra destaca a carência de uma literatura feminina em prol da educação, direitos e deveres das mulheres.

Maria Lacerda tinha consciência de que seu novo livro não seria bem visto em uma sociedade conservadora e tradicionalista, pois tratava de questões relacionadas ao feminismo, ao sufrágio e ao que ela considerava um dos maiores empecilhos para o progresso da mulher: a religião.

Renovação parece ter tido circulação mais ampla do que Em torno da educação, como apontam os "juízos de leitura" ${ }^{5}$ publicados sobre o livro, que partem de lugares diversos do país, como São Paulo e Rio de Janeiro, e até mesmo de fora do Brasil, como o vindo de Portugal.

Além de informações sobre a circulação de seu livro, os "juízos de leitura" revelam informações importantes, como o reconhecimento dado a Maria Lacerda como intelectual de seu tempo. Esse reconhecimento partia de pessoas de destacada importância, como Manoel Bomfim, que, além de indicar o trabalho da professora como merecedor de reconhecimento dentro da literatura social, ainda valorizava a opinião que a mesma poderia emitir sobre um de seus livros mais importantes: Lições de Pedagogia. Nesse caso, é preciso sinalizar que Maria Lacerda passou de uma posição de quem solicita leitura para a de interlocutora, o que indica o seu progressivo reconhecimento no campo.

Se no livro Em torno da educação a dedicatória se direcionou ao pai, em Renovação a homenagem foi direcionada à mãe de Maria Lacerda: "Tu que tanto me animaste no decorrer desta obra... Resignada e boa, cujos olhos se enchiam de pranto ao ouvir a leitura dessas páginas... Aceita, ó Mãe, a homenagem máxima do amor filial. É o mais carinhoso beijo que lhe posso dar" (MOURA, 1919, p. 5).

\footnotetext{
${ }^{5}$ Os chamados juízos de leitura eram as críticas publicadas sobre os livros que eram publicados na época.
} 
Logo após a dedicatória, uma espécie de aviso inicial abre o livro, como uma forma de alerta a possíveis leitoras. Pela primeira vez é possível identificar uma escrita totalmente diferenciada, uma escrita desafiadora, com palavras vibrantes algumas em caixa alta -, que expõe, até mesmo com certa rebeldia, um novo olhar sobre a educação, a sociedade, a religião e a política. Uma escrita destinada à mulher, que continuava sendo o alicerce da educação do futuro, porém com uma nova roupagem, a do feminismo.

A razão desse livro é simples. Estudei sozinha. Eu mesma me indicava os autores que devia ler. Conheci-os, uns através dos outros. E lia tudo: livros de filosofia, lógica, pedagogia, psicologia, moral, etc., etc. - procurando interpretar. Que soma de prazeres intensos! Páginas e páginas eu devorava ativamente. E minha alma se extasiava de tantas maravilhas e sentia turbamentos, arroubos indescritíveis (MOURA, 1919, p. 11).

A fala de uma autoeducação é constante nos escritos de Maria Lacerda. A autora dá a entender que não teve direcionamentos institucionais para os estudos que realizava, que os fazia sozinha, com interesses advindos da necessidade de se educar, seja para o desenvolvimento da sua profissão, seja para a sua condição de mulher.

A partir das leituras e dos conhecimentos adquiridos, Maria Lacerda afirmava que se sentia renascer em si mesma. Essa "renovação" se deu logo após a escrita de Em torno da educação, em que os primeiros aplausos e os primeiros espinhos fizeram com que traçasse um novo plano na ordem de suas publicações: "esperam de mim um livro nos moldes do que eu idealizara” (MOURA, 1919, p. 16). No livro, revela que fez um "balanço" nas suas concepções a partir dos estímulos e das apreciações recebidos, sobretudo de José Oiticica.

A própria Maria Lacerda observava que estava longe dos primeiros passos que havia dado. Em sua autobiografia, revelou que Em torno da Educação teria sido um "horror", livro "patriótico", "burguesíssimo", "cheio de preconceitos e dogmatismos":

Foi muito bem recebido pela crítica, aplaudidíssimo (pudera! Se era a defesa incondicional da sociedade vigente!). José Oiticica viu nele algo que Ihe interessava sob o ponto de vista de uma futura rebelde. Conheci-o através de larga correspondência. Veio para mim com as mãos cheias de literatura revolucionária. Sorvi tudo aquilo e muito mais e dei um salto na minha evolução (MOURA, 1919, p. 12). 
A interlocução com José Oiticica dá evidências do início de interesse pelos ideais e leituras anarquistas. Entretanto, enveredar nesse novo campo de ideias era algo que a preocupava, pois, um ano antes, defendia as causas da política republicana, os ideais de nação e de civilização em moldes europeus, tão caros aos políticos do momento. Assim, para fugir à ideia de contradição em seus escritos, a professora mineira buscou justificar a nova defesa que faria através da necessidade das mudanças, seja na natureza, seja na vida humana, que acontecem no dia a dia e que servem para a manutenção e para o aprimoramento da vida:

E se alguém achar que há contradições entre as ideias precedentes e de hoje, sem ter a pretensão de comparar, responderei como Vitor Hugo: J'ai grandi! (eu cresci). Todos crescem e tudo evoluciona sem haver contradições. Não se despojam os pássaros das velhas penas para encobrir-se de novo no arminho sedoso de um vestuário mais formoso e quente? As nossas células não se substituem para nos dar vida? As grandes árvores como as pequenas nascem, crescem, perdem as folhas, renascem em rebentos que dão flores e frutos. Depois, de novo, despojamse das folhas e parece que vão mirrar (MOURA, 1919, p. 13-14).

Justificava, ainda, pelo dever que dizia ter com a mulher brasileira, de construir para elas um livro esclarecedor, "um livro forte e útil", no qual elas pudessem conhecer o mundo em que viviam, "o mundo dos livros bons que ensinam a viver” (MOURA, 1919, p. 13). Só assim deixariam de ser ingênuas e de acreditar na felicidade que os homens diziam lhes oferecer.

Em Renovação, Maria Lacerda deixou de usar palavras e expressões republicanas, como nação e pátria, para fazer uso de outras voltadas para a esfera social, como sociedade, "energia social" e "bem social". Assim, mais do que forjar uma identidade nacional, a professora demonstrava o desejo de lançar luzes sobre os problemas sociais, típico do movimento anarquista da época. Um desses problemas seria o tratamento dado à mulher pela sociedade naquele período. Maria Lacerda de Moura apontava a submissão da mulher quase ao papel de escrava do marido: "Já ouvi um rapaz casado de poucos dias dizer que sua mulher, forçosamente, havia de abdicar da faculdade de pensar para dizer amém a todos os seus raciocínios - no caso que quisesse ser feliz!” (MOURA, 1919, p. 22). Outro relato da realidade de Maria Lacerda de Moura ainda é trazido para elucidar a situação: 
Infelizmente tive o pesar de assistir uma cena doméstica entre um casal de amigos meus no qual o marido, num momento de expansão nervosa disse à esposa: "se tivesses dignidade não estaria mais nessa casa". A mulher, que conhece as infidelidades do marido e o aceita, ainda não merece o seu respeito. Se a mulher fosse menos sentimentalista e mais alimentasse as fibras do seu caráter, se soubesse, por si, prover honestamente as suas necessidades e trabalhasse para conseguir igual salário não teria a desgraça de ouvir frases como aquela. A pobre senhora chorou toda a sua mágoa em lágrimas inúteis. E os filhos? O nome? O escândalo? - Preconceitos!! (MOURA, 1919, p. 25).

É dentro desse contexto que Maria Lacerda se voltou, em seu livro, para o movimento destinado a esclarecer e fazer reconhecer os direitos das mulheres: o feminismo. Para ela, os homens, "nas suas exigências egoísticas", não mais poderiam ser autoritários com uma mulher instruída e conhecedora dos seus direitos. Ao mesmo tempo, deixava claro que o homem nunca daria, por si só, lugar à mulher na sociedade. Assim, era preciso que a mulher buscasse conhecimento:

A mulher brasileira não saberá bem amar a sua bandeira enquanto essa bandeira que representa a nação, Ihe não explicar as divisas: ordem e progresso. Linda divisa, mas, por ora incompreensível para a metade do povo brasileiro. Que ordem é essa que, para ser estabelecida não tentou arrancar a mulher da opressão, dos preconceitos da sociedade tola e da tirania do serviço doméstico obrigatório para o nosso sexo? Que progresso é esse que sempre quer colocar a mulher na dependência do homem e lhe não pode restituir o papel de igual e companheira e sim Ihe distribui o de subalterna (MOURA, 1919, p. 28-29).

Para ela, muitos problemas relativos aos direitos das mulheres se davam em função da sua pouca ou nenhuma instrução. As leis brasileiras, as instituições e a sociedade como um todo conspiravam contra a mulher e seus direitos. Para esclarecer tal fato, fazia menção às conquistas femininas na Inglaterra, onde já era permitida a formação das mulheres como médicas, professoras, banqueiras, jornalistas, enfim, em tudo o que se julgava capaz de realizar. Em contraposição, expõe que, no caso brasileiro, a mulher estava exposta ao poder patriarcal, que anulava a sua participação e voz na sociedade:

No Brasil, para que uma moça seja professora primária, precisa exibir documentos em seu favor, partidos do delegado de polícia local, do Juiz de Direito e o documento do marido ou pai, autorizando a nomeação, dando o seu consentimento. Que vergonha! E quase sempre é o marido ou pai quem mais deseja o miserável ordenado, quem mais anseia pela nomeação e quem vai até a coletoria receber o dinheiro e às vezes o distribui (MOURA, 1919, p. 46). 
Ao tratar de uma das grandes defesas do feminismo, o sufrágio, Maria Lacerda esclarecia que não partilhava da ideia do voto enquanto participação da mulher na sociedade. Para ela, não seria o direito ao voto que traria felicidade à mulher, que garantiria a ela a saída de um estado de submissão, de miséria social, mas, sim, a sua participação direta na legislação, atenuando os inconvenientes provindos de interesses masculinos, modificando-a para o benefício da coletividade. Isso só seria possível se as mulheres fossem eleitas. Nesse caso, a sua atuação política se voltaria não só para a defesa de suas causas de mulher, mas também para o combate da opressão dos mais pobres e fracos:

Eu quero a mulher com direitos políticos para combater o álcool, o jogo, a prostituição, a mendicidade exploradora, para criar escolas profissionais onde 0 trabalho da criança não seja explorado, para abrir asilos às crianças desamparadas, postos de socorro ou auxílio às mães, postos de saúde pública e higiene, assistência médico-dentária, associações operárias para fazer florescer as ciências e as artes, proteger a mulher criando-lhe profissões e meios que the permitam viver honestamente, etc. [...] O seu partido deverá ser o dos escravos modernos, dos oprimidos, dos fracos e indefesos, o partido que clama implorando apenas o direito de igualdade (MOURA, 1919, p. 91).

Segundo Pinto (2003), o feminismo no Brasil teve diferentes manifestações, que podem ser classificadas em duas tendências que tiveram início no final do século XIX e se estenderam para as primeiras décadas do século XX. A primeira tendência, conhecida como "feminismo bem comportado", focava o sufrágio, tendo como líder mais expoente Bertha Lutz. Já a segunda tendência, o "feminismo malcomportado", buscava, além do direito político, o direito à educação, à libertação da dominação masculina, abordando assuntos impróprios para a época, como sexualidade e divórcio. A autora ainda sinaliza para uma terceira vertente, na qual, para ela, Maria Lacerda estaria inserida, que seria o "menos comportado dos feminismos", manifesto no movimento anarquista, que, além da busca pelos direitos já citados, defendia a construção de uma sociedade libertária, sem hierarquias, solidária, de vivência para o bem comum.

Além da crítica ao sufrágio feminino, Maria Lacerda de Moura escreveu sobre aquela que mais concorreria para a conservação da ignorância da mulher, a religião. Em sua visão, raras seriam as mulheres que teriam coragem para ler obras 
condenadas por uma ou outra Igreja, obras que ensinavam a raciocinar, a seguir apenas os ditames de uma consciência esclarecida:

Uma senhora das minhas relações fez uma promessa de ficar um ano sem ler! Que coisa horrível! E qual o resultado prático de tamanho sacrifício? Só vejo na tal promessa um meio mais seguro de cultivar a ignorância e, portanto, o mal social. Eu lhe disse que assumiria a responsabilidade do pecado infringido se ela aceitasse desligar-se de tão absurdo compromisso - não aceitou e riu-se por achar que eu não podia ter atribuições para tanto (MOURA, 1919, p. 116-117).

Esclarecia que sua pretensão não era condenar esta ou aquela religião: "Respeito todos os ideais, todos os cultos ou igrejas. O que penso é que a mulher não pode ficar cega diante de um homem igual aos outros, de uma opinião que pode ser erronia ou apaixonada ou ignorante, diante de livros que podem conter falsos raciocínios” (MOURA, 1919, p. 118). Mesmo sendo espírita, Maria Lacerda não atribui a nenhuma religião a legitimidade para a formação moral de uma pessoa. Para ela, a moral independia das religiões, pois se constituiria a partir de uma crença comum, a fraternidade universal, de respeito mútuo e de valorização do ser humano, independentemente de sua raça.

Ao discorrer sobre o tema, Maria Lacerda avaliava que sabia da extensão do perigo que corria o seu "pobre" livro: "Sinto os ódios que me vão acompanhar nas suas páginas ditadas pelo meu coração sensível, pelo meu caráter sincero e franco". Dizia que seu espírito seria tolerante para com esses atos, que seus princípios não a deixariam reagir, e que a revolta só partiria do seu íntimo: "Não terei, certamente, calorosos aplausos. O que fazer?” (MOURA, 1919, p. 137).

No contexto exposto, é possível perceber que, em Renovação, Maria Lacerda via a mulher de forma mais ampla, para além do papel de mãe e professora. A figura feminina passa a ser colocada em várias posições sociais, sobretudo naquelas em que estivessem como representantes na defesa pelos direitos das próprias mulheres. Do mesmo modo, a obra trouxe um entendimento mais amplo da condição da criança, sinalizando as múltiplas relações que a envolvia: com os adultos, com a sociedade, a cultura, entre outros (KUHLMANN JR.; FERNANDES, 2004). Nesse sentido, é possível considerar que a autora passou a pensar as particularidades da mulher nessa relação complexa com a criança como ser social. 


\section{Considerações finais}

É difícil enquadrar Maria Lacerda entre as coordenadas sociais, políticas e históricas previamente conhecidas. Seu pensamento plural e multifacetado foi presente em toda a sua vida. Foi defensora da República Brasileira, mas foi também sua crítica, quando aderiu ao anarquismo como forma de resistência ao governo existente. Valorizou a escola como propulsora da civilização para, logo depois, identificá-la como instituição de domínio e cerceamento humano. Por ter tido e publicado diferentes ideais, Maria Lacerda foi, e ainda é, considerada por muitos pesquisadores uma intelectual contraditória e até mesmo rebelde.

Não foi diferente a forma como tratou da questão da educação da mulher. Vista por diferentes vieses, tal educação foi pensada ora pelo bem comum, o da civilização brasileira, ora pelo bem da própria mulher, que passou a ser vista como sujeito singular não só com deveres, mas também com direitos. É nesse contexto multifacetado que podemos compreender a escrita de Maria Lacerda de Moura sobre a mulher: como alguém que ousou sair de um discurso estabelecido, criando caminhos e estratégias sobre aquilo em que acreditava.

Apesar de sua condição de espírita, anticlerical e feminista ser considerada inadequada para a sua condição de mulher e professora de Escola Normal, não se pode considerar Maria Lacerda uma mulher fora de seu tempo. Pelo contrário, ela foi o espelho das questões da sua época, dos desafios pelos quais passaram as mulheres no início do século XX. Imersa no tempo em que viveu, traduziu-se como uma intelectual engajada com as causas que presenciou e buscou atuar como uma espécie de bússola ao apontar caminhos para a melhoria da sociedade de seu tempo. Muito provavelmente foram essas questões que fizeram com que seu pensamento se difundisse para caminhos tão diferentes, favorecendo a tomada de posições tão distintas no debate sobre a educação e a mulher.

Evidentemente, a formação familiar e institucional contribuiu para que Maria Lacerda se colocasse diante dos revezes de seu tempo, alicerçando seus ideais e os embates que travou, com crenças e conhecimentos. Seu pai, apontado por ela 
própria como seu principal educador e incentivador, dera-lhe a confiança na evolução da humanidade, não somente aquela aliada ao plano espiritual das reencarnações conforme ensinava a doutrina espírita, mas também aquela na qual a ação de cada um opera transformações significativas nas necessidades de uma época, tanto no plano individual como no coletivo.

Mesmo não tendo tido uma formação institucional voltada especificamente para as ações que desenvolveu ao longo de sua trajetória como educadora, é possível identificar, tanto na escola católica como na Escola Normal em que estudou, experiências que possibilitaram o seu crescimento reflexivo, mesmo ao imporem condutas distantes e diferenciadas daquelas das quais partilhava em sua família. Aliado a essas formações estaria, ainda, o autodidatismo — ou a autoeducação, como ela própria gostava de chamar - , que pode ser considerado a principal chave de leitura para o entendimento da atuação dessa intelectual, sobretudo com relação ao seu projeto de educação da mulher.

A mudança de um ideal republicano para uma postura mais libertária, exposta claramente em Renovação, não fez com que Maria Lacerda abandonasse sua crença na ciência como condição de transformação e melhoria da educação da mulher. Pelo contrário, seus estudos se tornaram o motor de suas novas ideias, apontando a importância da ciência para a condução de uma formação feminina mais racional e livre das amarras sociais. Nesse cenário, tanto a mulher como a criança seriam beneficiadas. A primeira com um maior esclarecimento sobre as suas potencialidades intelectual e social, a segunda com um ensino mais centrado em seus interesses e subjetividade, já que alicerçado por uma educação bem alicerçada que fora dada à sua maior educadora: a mulher.

Se Maria Lacerda já tem um lugar de reconhecimento como liderança feminista e anarquista, este artigo pretendeu lançar luzes sobre a sua atuação como educadora, sobretudo, na proposição de um projeto de educação da mulher, que se deu ao longo dos seus dois primeiros livros. Por ser uma mulher multifacetada e que esteve em constante movimento, muito ainda poderá ser explorado e dado a conhecer sobre essa figura fundamental para pensarmos o lugar da mulher educadora na sociedade ao longo do século XX. 


\section{Referências}

DIAS, M. A. L. O espirito da educação: Maria Lacerda de Moura (1918-1935). Dissertação (Mestrado em Educação) — Faculdade de Educação, Universidade de São Paulo, São Paulo, 1999.

FERNANDES, R. Estratégias de ironia e de sarcasmo contra a educação feminina em Portugal (séculos XVIII/XIX). Faces de Eva, Lisboa, n. 9, p. 13-27, 2003.

FOUCAULT, M. Microfísica do poder. Rio de Janeiro: Graal, 1979.

FOUCAULT, M. História da sexualidade I: a vontade de saber. Rio de Janeiro: Edições Graal, 1984.

FOUCAULT, M. Resumo dos Cursos do Collége de France (1970-1982). Rio de Janeiro: Edições Graal, 1997.

JINZENJI, M. Y. Cultura impressa e educaşão da mulher no século XIX. Belo Horizonte: UFMG, 2010.

KUHLMANN JR., M.; FERNANDES, Rogério. Sobre a história da infância. In: FARIA FILHO, L. M. (Org.). A infância e a sua educação: materiais, práticas e representações (Portugal e Brasil). Belo Horizonte: Autêntica, 2004. p. 15-33.

LÉVY, B.-H. Elogio dos intelectuais. Rio de Janeiro: Rocco, 1998.

LOURO, G. L. Mulheres na sala de aula. In: DEL PRIORI, M. (Org.). História das mulheres no Brasil. São Paulo: Contexto, 2009. p. 443-481.

MALUF, M.; MOTT, M. L. Recônditos do mundo feminino. In: NOVAIS, F. A. (Org.). História da vida privada no Brasil: República da Belle Époque à Era Republicana. São Paulo: Companhia das Letras, 1998. p. 367-422.

NUNES, S. A. Histeria e psiquiatria no Brasil da Primeira República. História, Ciências, Saúde-Manguinhos, Rio de Janeiro, dez. 2010. Disponível em: https:/ /www.scielo.br/scielo.php?script=sci_arttext\&pid=S0104-59702010000600006\&lng=pt\&tlng=pt

PERROT, M. Minha história das mulheres. São Paulo: Contexto, 2005.

PINTO, C. R. J. Uma história do feminismo no Brasil. São Paulo: Fundação Perseu Abramo, 2003.RAGO, M. Do cabaré ao lar: a utopia da cidade disciplinar e a resistência anarquista: Brasil 1890-1930. São Paulo: Paz e Terra, 2014.

SCHMIDT, R. Repensando a cultura, a literatura e o espaço da autoria feminina. In: NAVARRO, M. H. (Org.). Rompendo o silêncio: gênero e literatura na América latina. Porto Alegre: Ed. da URGS, 1995.

VIEIRA, C. E. Intelectuais e educação. Pensar a Educação em Revista, Belo Horizonte/ Curitiba, ano 1, v. 1, p. 1-23, abr./jun. 2015.

WOOLF, V. Profissões para Mulheres. Rio de Janeiro: Paz e Terra, 1996. 


\section{Fontes Documentais}

MOURA, M. L. Em torno da educaşão. [S.1.]: Livraria Teixeira, 1918.

MOURA, M. L. Renovação. Belo Horizonte: Tip. Athene, 1919b.

MOURA, M. L. Autobiografia. O Combate, São Paulo, 3 ago. 1929, n. 5, 110, p. 3.

MOURA, M. L. Profissão de fé. A Lanterna. São Paulo, 9 fev. 1935, n. 388, p. 3.

RECEBIDO: $31 / 08 / 2020$

APROVADO: 03/10/2020

RECEIVED: 08/31/2020

APPROVED: $10 / 03 / 2020$

RECIBIDO: $31 / 08 / 2020$

APROBADO: 03/10/2020 